\title{
Birmingham Medical Research Expeditionary Society 1977 Expedition: Changes in renal function observed during a trek to high altitude
}

\author{
J. P. Delamare* \\ M.R.C.P. \\ G. T. JONES $\dagger$ \\ Ph.D. \\ * Queen Elizabeth Hospital and $\dagger$ Department of Physics, University of Birmingham, \\ Chancellors Court PO Box 463, Birmingham
}

\begin{abstract}
Summary
Changes in renal function were observed in 17 subjects during the course of a trek to high altitude. Comparison was made between these changes and the clinical assessment of acute mountain sickness (AMS).

Periods of natriuresis occurred during ascent and descent, that during ascent being related to a fall in plasma aldosterone. Alterations in serum and urinary potassium suggested that potassium retention occurred during the ascent to altitude.

No significant correlation occurred between changes in renal function and the severity of AMS before the illness being clinically apparent. When this was so, the severity of AMS correlated with a decreasing urine output, increasing positive fluid balance and a decreasing excretion of sodium and potassium; these changes were produced in part by a decrease in glomerular filtration rate.
\end{abstract}

\section{Introduction}

Many studies of renal function at high altitude have been made (Rennie and Joseph, 1970; Slater et al., 1969; Frayser et al., 1975). Various changes have been documented but only a few workers, such as Singh et al. (1969), have attempted to correlate the changes observed with the severity of acute mountain sickness (AMS). The latter authors found that individuals who had oliguria at altitude had an increased incidence of AMS, although the cause of the oliguria was not elucidated.

The aims of the present study were twofold; firstly to observe the physiological changes in renal function during the course of a trek to high altitude; secondly to observe any differences in renal function in those who suffered with AMS compared with those who did not.

\section{Method}

The 17 members of the BMRES already described (Fletcher, 1979) took part in the study.

The subjects ascended over 11 days from 700 to $5050 \mathrm{~m}$, remained at this height for 2 days, then descended over a further 3 days to $2550 \mathrm{~m}$. One subject had to be escorted to lower altitude on day 11 owing to AMS and both he and his escort took no further part in the study.

Twenty-four-hr urine collections were made in all subjects and the volume measured. A $25-\mathrm{ml}$ aliquot of each collection was stored with sodium merthiolate $(0.1 \%)$ at the ambient temperature during the 4 weeks of the trek and at $-20^{\circ} \mathrm{C}$ on returning to England. Daily plasma specimens were obtained during the initial 13 days (Howell and Cove, 1979). Each subject's daily fluid intake was measured and recorded in a personal diary but the water and electrolyte content of the diet was not measured and no estimation was made of the sweat and insensible fluid losses.

The samples were stored for up to 4 months in England at $-20^{\circ} \mathrm{C}$ and thawed immediately before analysis. The urinary and plasma sodium and potassium were determined by flame photometry whilst urine osmolality was measured by depression of freezing point, using a Precision Instruments Inc., osmometer. The plasma and urinary creatinine concentrations were determined using the alkaline picrate method as adapted to the 'auto analyser' and the net titratable acidity was assessed by the method of Jørgenson (1957). Plasma aldosterone levels were measured during the first 13 days by radio-immune assay, using the method of Fraser, Guest and Young (1973).

The clinical rank order for AMS (Fletcher, 1979) was related to the daily results of each investigation and significance was assessed using the Spearman's rank correlation coefficient. The significance of the comparison of mean urinary sodium with urine volume was assessed by the linear correlation coefficient, as was the relationship between plasma aldosterone and the urinary sodium potassium ratio. The Student $t$-test was utilized to test the significance of changes in the daily results.

\section{Results}

Three distinct climatic zones were faced during the course of the trek. Hot humid jungle conditions 
were encountered on days 1-14, causing profuse sweating. Walking on days 5-8 and 14-16 was in a warm temperate clime, contrasting with the dry and cold conditions pertaining at high altitude on days 9-13. Sporadic attacks of vomiting and diarrhoea occurred during the first 7 days but did not present a problem thereafter. were associated with natriuresis (Fig. 3). Unlike the sodium, the daily urinary potassium excretion showed no significant changes during the first 14 days but increased on days 15 and 16 (descent 2750-1450 m) (Fig. 5). The significance of these changes when compared with day one was $P<0.01$ and $P<0.001$ respectively. The plasma potassium

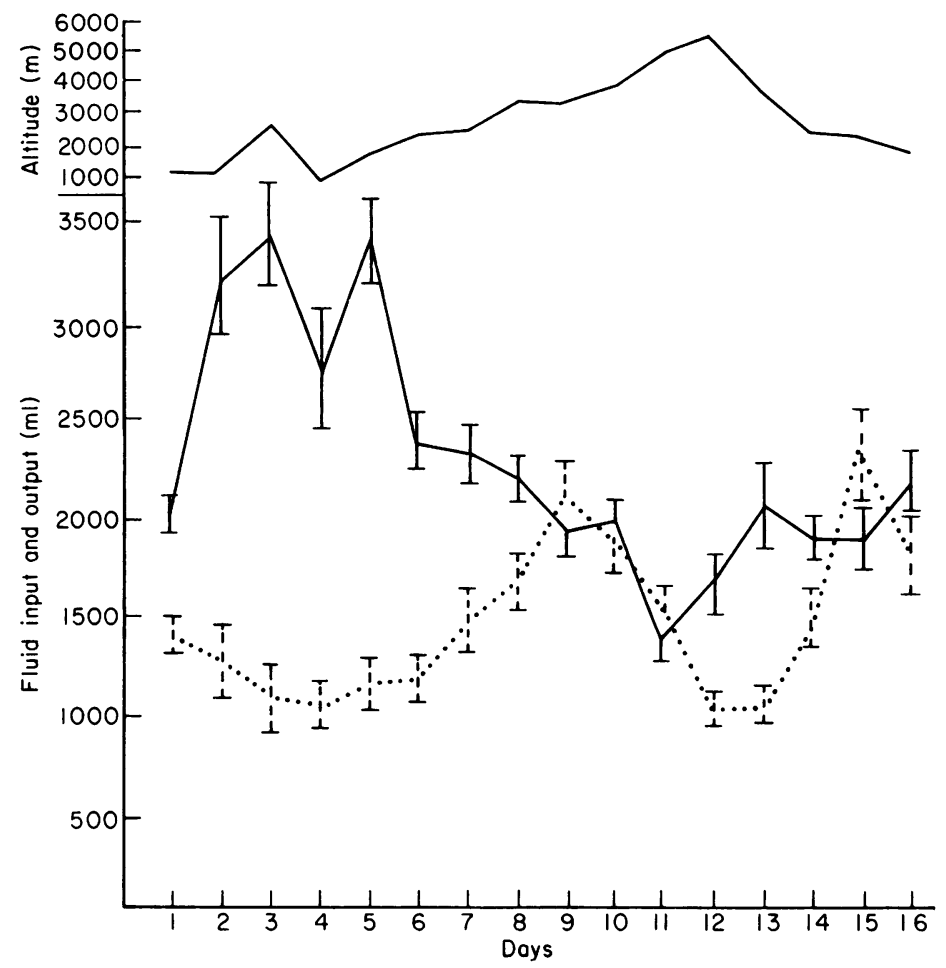

Fig. 1. Altitude in metres against daily fluid input $\mathrm{ml} \pm$ s.e. mean ( $\longrightarrow$ ) and mean daily urine output $\mathrm{ml} \pm$ s.e. mean $(\cdots \cdots)$ for days $1-16$.

The mean fluid input and urine output (Fig. 1) revealed a large positive fluid balance during the initial 5 days and evidence for fluid retention occurring at this time has been presented (Howell and Cove, 1979). A diuresis (urine output $>$ fluid input) occurred on the ninth day during ascent (a rest day at $3500 \mathrm{~m}$ ) in 14 out of 17 subjects and during descent on day $15(2750-2550 \mathrm{~m})$ in 11 of the 15 subjects. No diureses occurred when the subjects were above $3800 \mathrm{~m}$ (day 12 and 13) (Fig. 2). The urine osmolality remained constant during the period of ascent diuresis (days 7-11) but rose at the end of diuresis (days 12-13) (Fig. 3).

The 24-hr urinary sodium excretion correlated significantly with the urine output during days 6-16 $(P<0.001)$, signifying that the 2 periods of diuresis increased during the first 13 days, being significantly higher on day 13 than on day one $(P<0.05)$ (Fig. 4).

Plasma aldosterone levels rose initially (days 1-4) but fell during ascent to high altitude (days 7-13). A significant negative correlation was observed between plasma aldosterone and the urinary : sodium potassium ratio $(P<0.001)$ (Fig. 4). The net titratable acidity of the urine fell with increasing altitude (Fig. 5) but also decreased on days 15 and 16 (descent 2750-1450 m), being significantly lower on day 16 than on day 5 although the altitude was identical $(P<0.001)$. No significant changes occurred in the creatinine clearance during the ascent or at high altitude (days 7-13). However, an isolated rise occurred on day 4 (Fig. 4) following the severe physical exertion of day 3 (1500-2850 m). 


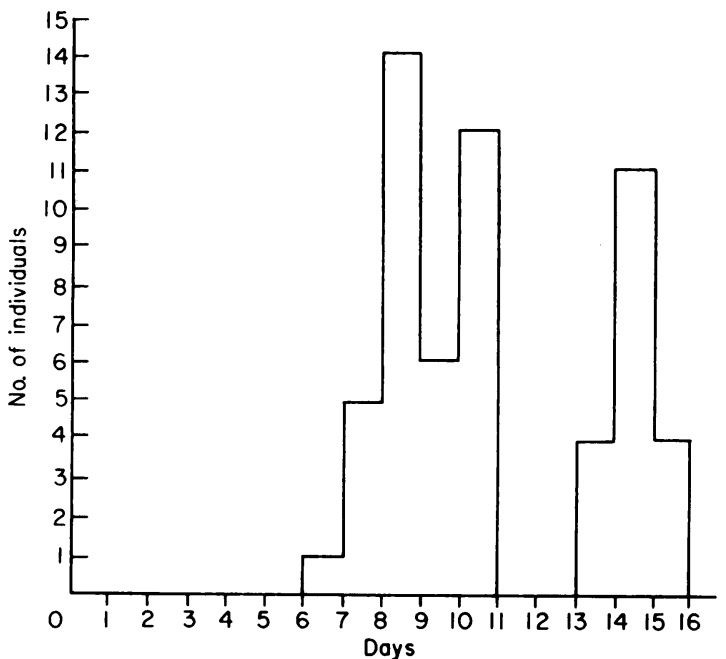

FIG. 2. Daily numbers of individuals with diuresis (urine output > fluid input) for days 1-16.

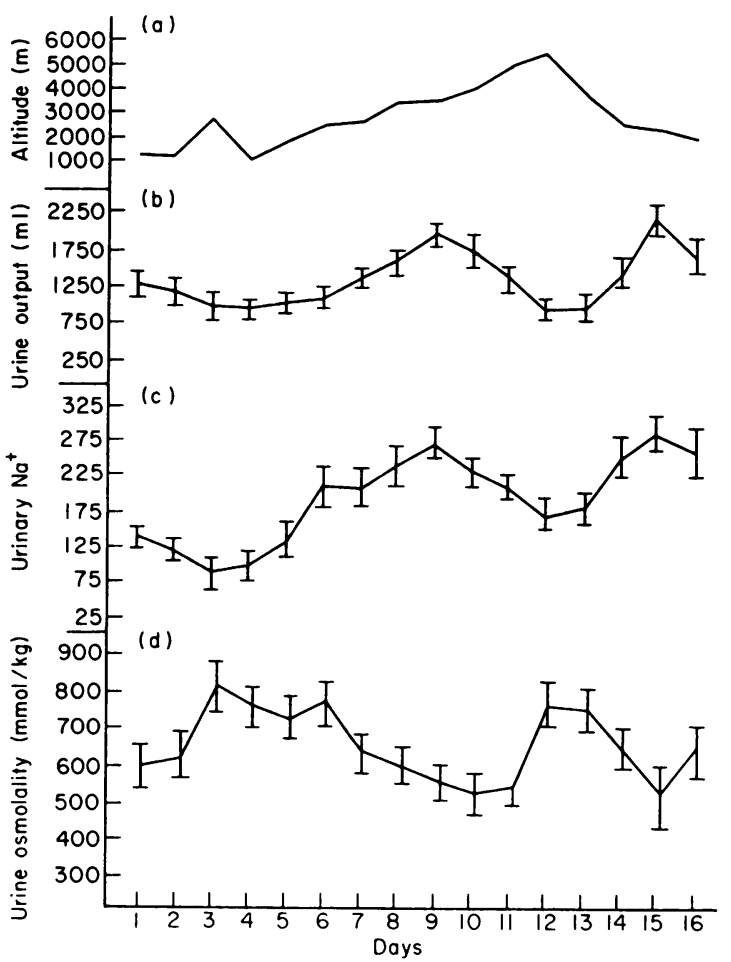

FIG. 3. (a) Altitude in metres; (b) mean daily urine volume $\mathrm{ml} \pm$ s.e. mean; (c) mean daily total urinary sodium excretion mmol \pm s.e. mean; (d) mean daily urine osmolality $\mathrm{mmol} / \mathrm{kg} \pm$ s.e. mean for days $1-16$.
The majority of the signs and symptoms of AMS appeared on day 11 (ascent $4250-5050 \mathrm{~m}$ ). On that day, urine output, but not fluid input, was correlated negatively with the clinical assessment of AMS $(P<0.05)$, as were sodium and potassium excretion $(P<0.001$ and $P<0.01$ respectively). The creatinine clearance and thus the glomerular filtration rate also exhibited a negative correlation with the severity of AMS on day $11(P<0.01)$. No significant correlation was found between plasma aldosterone levels and the severity of AMS.

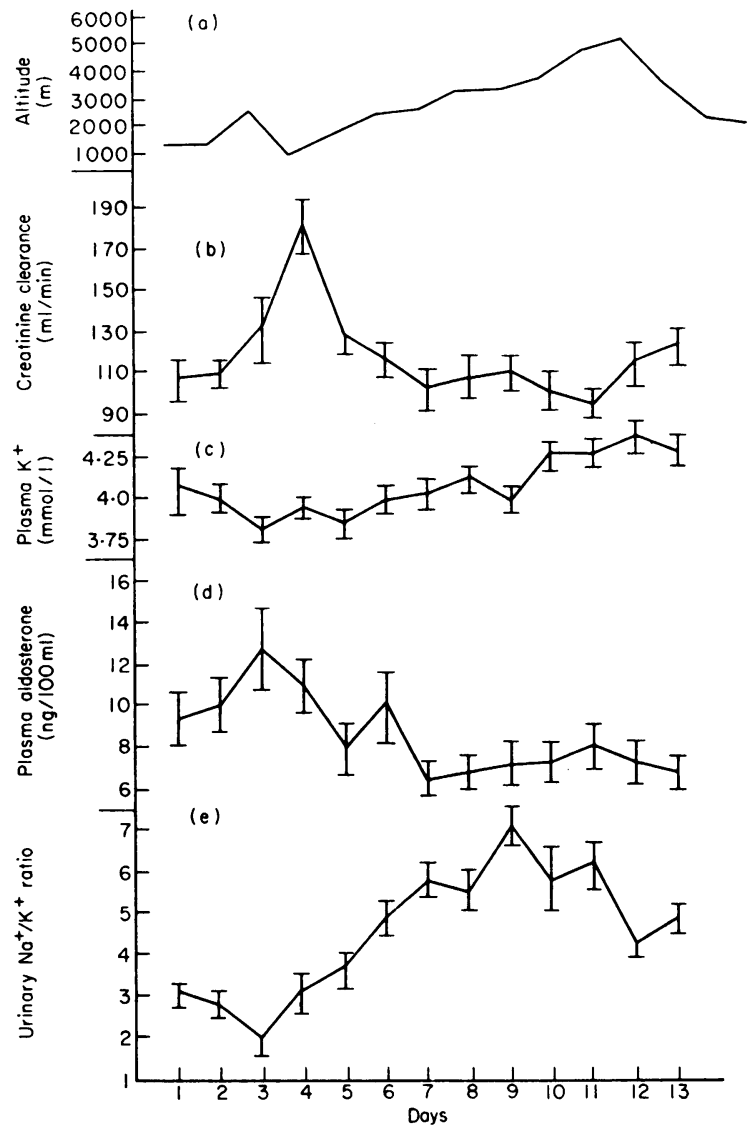

FIG. 4. (a) Altitude in metres; (b) mean daily creatinine clearance $\mathrm{ml} / \mathrm{min} \pm$ s.e. mean; (c) mean daily plasma potassium concentration $\mathrm{mmol} /$ litre \pm s.e. mean; (d) mean daily plasma aldosterone concentration $\mathrm{ng} / 100 \mathrm{ml}$ \pm s.e. mean; (e) mean daily urinary sodium : potassium ratio \pm s.e. mean for days $1-13$.

\section{Discussion}

The striking feature of this study, demonstrated in Fig. 2, was the diuresis which occurred during ascent and descent. As both periods of diuresis were associated with a natriuresis (Fig. 3) a decreased 


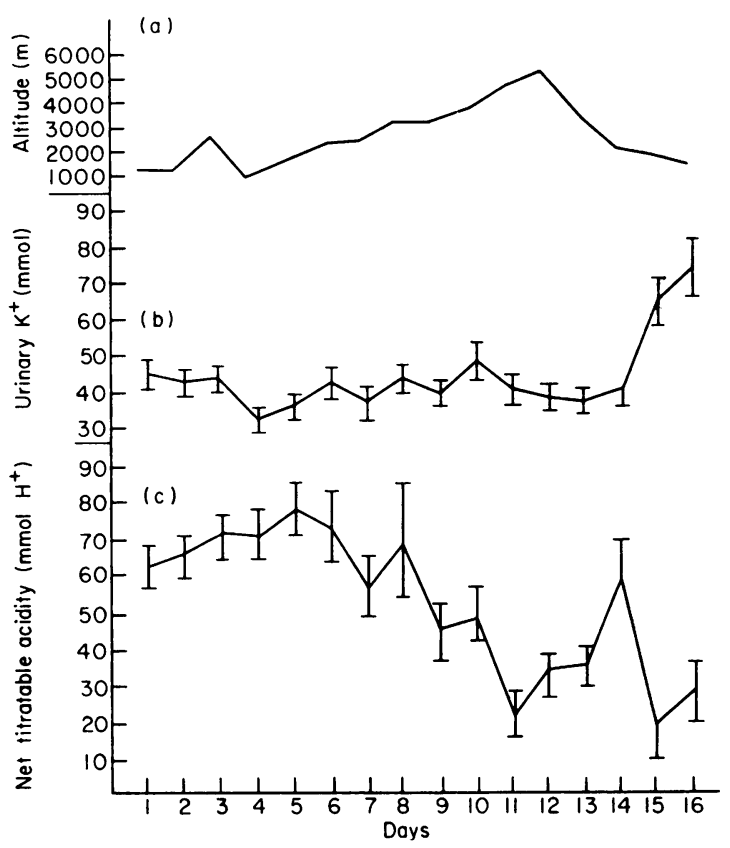

Fig. 5. (a) altitude in metres; (b) mean daily total urinary potassium secretion mmol \pm s.e. mean; (c) mean daily net titratable acidity $\mathrm{mmol} \pm$ s.e. mean for days 1-16.

aldosterone effect might have been a mediating factor. This was found to be the case in the ascent diuresis. No aldosterone levels were taken during descent. However, whether altitude was in any way responsible for these diureses is debatable. Howell and Cove (1979) have shown that the fluid retention preceding the first period of diuresis (days 7-11) occurred whilst at a relatively low altitude on days 2-4 and was probably related to sustained unaccustomed exercise (Williams, 1979). Diuresis on arrival at high altitude has not been a feature of previous studies which have utilized mechanical transport for ascent (Consolazio et al., 1972; Krzywicki et al., 1971). However, Singh et al. (1969) observed an effective diuresis of $930-4700 \mathrm{ml}$ in 46 subjects who were immune to the development of AMS. Unfortunately the mode and duration of ascent was not specified. Could it be that the diuresis so often experienced by mountaineers ascending to high altitude is partly or wholly a response to fluid retention produced by severe exertion? Low altitude studies are required to assess the effect of sustained exercise on fluid balance (Williams, 1979).

The descent diuresis might reflect fluid retention on days 12 and $13(5050 \mathrm{~m})$. Despite an increasing fluid input, urine output decreased on these days
(Fig. 1) with an associated increase in urine osmolality. These changes taking place in the presence of a low plasma aldosterone suggests that an increase in antidiuretic hormone (ADH) might have produced fluid retention but no reliable information is available in the literature concerning the effects of altitude on ADH.

Although no estimation was made of daily electrolyte input the diet varied little throughout the trek and thus changes in the daily intake were not held responsible for the increase in potassium excretion observed during days 15 and 16 (descent, $2750-1450 \mathrm{~m}$ ). This increased excretion together with the small but significant $(P<0.05)$ rise in plasma potassium during ascent suggests that retention of potassium may have occurred during the initial 13 days. Evidence of potassium retention at altitude was observed by Slater et al. (1969), who suggested that a decrease in sodium/potassium exchange in the distal tubule of the nephron may have been partly responsible. In the present study the observed fall in plasma aldosterone on days 7-13 (Fig. 4) could have facilitated potassium retention by a similar mechanism. This increased potassium excretion may also have been responsible for the paradoxical fall in net titratable acidity observed on days 15 and 16, owing to the potassium competing with the hydrogen for sodium exchange in the distal tubule (Rector, Buttram and Seldin, 1962).

The findings of a negative correlation between urine output and the severity of AMS agree with the work of Singh et al. (1969) and would appear to be related to a fall in glomerular filtration rate, although the factors underlying this fall are elusive. A decrease in plasma volume would not appear to be responsible as no significant rise was observed in the packed cell volume. Impairment of glomerular function is also unlikely as no significant increase in albuminuria was noted in the subjects who suffered from AMS (Bradwell, 1979).

It is of interest to note that the changes in renal function which correlated with AMS occurred after the illness was clinically apparent. It would therefore appear unlikely that finding changes in renal function would facilitate identification of susceptible individuals before the onset of AMS.

\section{Acknowledgment}

We wish to thank the MRC Blood Pressure Unit, Glasgow Royal Infirmary, and especially Mary Ingram for the aldosterone estimations.

\section{References}

Bradwell, A.R. (1979) BMRES 1977 expedition: Serum and urine proteins during a high altitude trek. Postgraduate Medical Journal, 55, 478. 
Consolazio, C.F., Johnson, H.L., KRzYwicki, H.J. \& DAws, T.A. (1972) Metabolic aspects of acute altitude exposure (4,300 metres) in adequately nourished humans. American Journal of Clinical Nutrition, 25, 23.

Fletcher, R.F. (1979) BMRES 1977 expedition: Signs and symptoms. Postgraduate Medical Journal, 55, 461.

Fraser, R., Guest, Sheena \& Young, Jessie (1973) A comparison of double-isotope derivative and radioimmunological estimation of plasma aldosterone concentrations in man. Clinical Science and Molecular Medicine, 45, 411.

Frayser, Regina, Rennie, I., Gray, G.W. \& Houston, C.S. (1975) Hormonal and electrolyte response to exposure to 17,500 ft. Journal of Applied Physiology, 38, 636.

Howell, A. \& Cove, D.H. (1979) Birmingham Medical Research Expeditionary Society 1977 Expedition: The diuresis and related changes during a trek to high altitude. Postgraduate Medical Journal, 55, 471.

JøRGENSEN, K. (1957) Titrimetric determination of the net excretion of acid/base in urine. Scandinavian Journal of Clinical and Laboratory Investigation, 9, 287.
Krzywicki, H.J., Consolazio, C.F., Johnson, H.L., Nielsen Jr, W.C. \& BarnhaRT, R.A. (1971) Water metabolism in humans during acute high altitude exposure (4,300 metres). Journal of Applied Physiology, 30, 806.

Rector Jr, F.C., Buttram, H. \& Seldin, D.W. (1962) An analysis of the mechanism of the inhibitory influence of $\mathbf{K}+$ on renal $\mathbf{H}^{+}$secretion. Journal of Clinical Investigation, 41, 611.

RENNIE, I.D.B. \& JoSEPH, BeTTY, J. (1970) Urinary protein excretion in climbers at high altitude. Lancet, i, 1247.

Singh, I., Khanna, P.K., Srivastava, M.C., Lal, M., Roy, S. \& SubramanYam, C.S. (1969) Acute mountain sickness. New England Medical Journal, 280, 175.

Slater, J.D.H., Williams, E.S., EdWards, R.H.T., EkINS, R.P., Sonksen, P., Beresford, C.H. \& MCLAUghlin, MAJORIE (1969) Potassium retention during the respiratory alkalosis of mild hypoxia in man: Its relationship to aldosterone secretion and other metabolic changes. Clinical Science, 37, 311.

Williams, E.S. (1979) Exercise and altitude. Postgraduate Medical Journal, 55, 492.

\section{Discussion}

Professor E. S. Williams: Your biphasic diuresis shows the first piece of evidence separating the effects of walking from the effects of altitude. It seems that the first diuresis was when you acclimatized to walking, followed by water retention due to hypoxia and then diuresis due to fast descent - all mountaineers will recognize the effects of descent.
A Participant: Was there a correlation between fluid balance (as well as urine volume) and AMS?

Dr J. P. Delamere: Yes. The fluid balance on days 11 and 13 correlated with the clinical assessment of AMS the more fluid retention the worse the AMS.

Professor Williams: A preliminary study gave similar results. 